Revista de la red interuniversitaria de estudios sobre las literaturas rioplatenses contemporáneas en Francia

$14 \mid 2016$

Levrero

\title{
El discurso y el dibujo : apuntes sobre la bizarra imaginación de Mario Levrero
}

\section{Julio Prieto}

\section{OpenEdition}

\section{Journals}

Edición electrónica

URL: http://journals.openedition.org/lirico/2278

DOI: $10.4000 /$ lirico.2278

ISSN: 2262-8339

Editor

Réseau interuniversitaire d'étude des littératures contemporaines du Río de la Plata

\section{Referencia electrónica}

Julio Prieto, «El discurso y el dibujo : apuntes sobre la bizarra imaginación de Mario Levrero»,

Cuadernos LIRICO [En línea], 14 | 2016, Puesto en línea el 07 junio 2016, consultado el 30 abril 2019.

URL : http://journals.openedition.org/lirico/2278 ; DOI : 10.4000/lirico.2278

Este documento fue generado automáticamente el 30 abril 2019.

\section{cc) $(1) \odot$}

Cuadernos LIRICO está distribuido bajo una Licencia Creative Commons Atribución-NoComercialSinDerivar 4.0 Internacional. 


\title{
El discurso y el dibujo : apuntes sobre la bizarra imaginación de Mario Levrero
}

\author{
Julio Prieto
}

1 “No cultivo las letras, sino las imágenes; y las imágenes están muy próximas a la materia prima, que son las vivencias". ${ }^{1}$ Esta declaración procedente de una entrevista apócrifa -“Entrevista imaginaria con Mario Levrero", el texto que cierra su colección de relatos $\mathrm{El}$ portero y el otro- puede servirnos de entrada al universo Levrero. En esta entrevista "imaginaria" -el autor se entrevista a sí mismo-, Levrero privilegia la imagen como el núcleo de su labor creativa : el hecho es sintomático y habla ya de la singular gravitación de lo imaginario en su escritura. Entre los autores modernos, Mario Levrero es sin duda uno de los más lúcidos y audaces en la exploración de lo que con Ludwig Wittgenstein llamaríamos la "vivencia visual" (das Seherlebnis). ${ }^{2}$ No obstante, la dicotomía que el autor "auto-entrevistado" plantea aquí entre letras e imágenes es hasta cierto punto engañosa lo que no debería sorprendernos demasiado en una entrevista, al fin, apócrifa. Más justo sería describir a Levrero como una suerte de "dibujante en letras" -un escritor dibujante de imágenes-vivencias-, toda vez que el rasgo eminente de lo que de manera aproximativa podríamos llamar "textualidad levreriana" es justamente una específica cualidad de circulación obsesiva entre las palabras y las imágenes.

2 Privilegiar el "cultivo de imágenes" en detrimento del "cultivo de las letras" podría tal vez leerse como un gesto sintomático de un giro epocal de las prácticas culturales, vinculable a la expansión global de la cultura audiovisual de masas y al desarrollo de las nuevas tecnologías de la información en las últimas décadas del siglo XX -eso que William Mitchell, entre otros, ha asociado al "giro pictorial" de las ciencias sociales y humanas, ${ }^{3}$ tras el "giro lingüístico" dominante en la filosofía y en la teoría cultural y literaria en los años 60 y $70 .{ }^{4}$ Sin descartar esta hipótesis, me interesa subrayar aquí lo que ese gesto supone en cuanto construcción de una determinada "figura de autor". ${ }^{5}$ La imagen del escritor "dibujante" propone una figura autorial notoriamente ex-céntrica, que opera en los márgenes de la institución literaria asociada al tradicional "cultivo de las letras", ${ }^{6}$ y 
que de alguna manera corresponde a la ecléctica serie de oficios y ocupaciones autoriales que Levrero ejerció a lo largo de su vida, muchas de las cuales implican el cultivo de un específico ingenio gráfico -entre otros oficios y ocupaciones más o menos estables Levrero fue inventor de crucigramas, chistes y acertijos, dibujante y guionista de cómics, ilustrador y escritor de cuadernos privados, actividades que desarrolló de forma paralela y a menudo complementaria a su producción como autor de novelas, relatos y experimentos narrativos de diversa índole. ${ }^{7}$

3 En una de sus "Irrupciones", como llamó a la serie de columnas publicadas en la revista Posdata entre febrero de 1996 y junio de 1998, y entre febrero y junio del 2000, Levrero reivindica lo "excéntrico" de una escritura vinculada al dibujar en cuanto actividad privada, que opone a la institución literaria que se definiría por la "publicación de libros". A partir de la cómica anécdota de un hombre que le conmina a explicarle "cómo se escribe un libro" -ante lo que se ve obligado a admitir su ignorancia-, Levrero observa : "Yo no había sabido comprender la diferencia entre escribir, y escribir un libro ; escribía lo que surgía, y eso podía ser un relato, o una novela corta, o una novela un poco más larga ; o un artículo humorístico, o un poema que jamás habría de mostrar a nadie. Y otras cosas, que salían sin otra finalidad que la de nacer, como por ejemplo dibujitos". ${ }^{8} \mathrm{Y}$ un poco más adelante agrega : "Hoy probablemente le diría que sí, que puedo enseñarle a escribir un libro, porque realmente hoy sé cómo se puede escribir un libro -aunque sigo sin saber cómo se hace para escribir- y sé que la ambición de publicar un libro es una ambición tan válida como muchas otras que a mí no me van ni me vienen (no es que no tenga ambiciones ; es que soy un excéntrico, y mis ambiciones no son compartibles)". ${ }^{9} \mathrm{En}$ la reivindicación de la "libertad de dibujo" de la escritura -la "libertad de trazar", diríamos con Roland Barthes ${ }^{10}$-, Levrero continúa una conspicua tradición de escrituras "de cuaderno" -una serie más o menos para-literaria que incluiría escrituras como las de Macedonio Fernández, Paul Valéry o Leonardo da Vinci (otro notorio escritor-dibujante). Ese proyecto de escritura miscelánea y errante -escritura de "dibujitos y otras cosas", no necesariamente destinada a la publicación de libros, aunque tampoco lo excluya de antemano- no se orienta a la instalación de una figura de autor "rentable" en el mercado o en un determinado campo cultural : antes bien se diría que desdeña y despilfarra el capital simbólico ligado al autor "profesional" -y a ese tipo de "belleza eficiente, seria, autoconsciente" que, como observa en otra de sus "Irrupciones", "abunda en las florerías". ${ }^{11}$

4 La construcción de la figura autorial del "escritor dibujante" es recurrente en las entrevistas de Levrero -imaginarias o no. Casi tanto como la exploración del "dibujo" de la escritura en sus narraciones -cuestión sobre la que volveré enseguida. En ese sentido es significativo que lo primero que confiesa haber escrito fuera el plagio, a los cinco años, de un cuento de hadas incluyendo las ilustraciones, y que su primera actividad regular como escritor fuera la elaboración, a los dieciséis, de un "diario mural" consistente en "hojas escritas y adornadas con fotografías, dibujos y recortes"12 -en cierto modo la entera producción levreriana emerge de este paradigma de "hojas escritas y adornadas con dibujos y recortes". Como no deja de ser significativo el hecho de que el primer mentor que nombra -quien le da el primer espaldarazo como autor y el primero a quien reconoce la autoridad de juzgar su escritura- no es un escritor o un crítico literario sino un pintor :

Siempre escribía, o dibujaba, y tiraba. El que me impulsó a no seguir tirando fue el "Tola" (José Luis) Invernizzi, gran pintor y gran hombre. No sólo consiguió que conservara lo que hacía, sino que me mantuvo vivo el interés por escribir especialmente La ciudad-y me sostuvo en el esfuerzo de concluir la novela, a lo 
largo de diez o quince días de trabajo continuo. Yo iba noche a noche a su casa y le daba a leer las páginas nuevas : él, invariablemente, decía : "Está bien, seguî". ${ }^{13}$ dibujar -"escribía o dibujaba"- en cuanto continuum creativo del que emerge su primera novela -lo que supone un determinado modelo de circulación no jerárquica entre distintas prácticas y disciplinas. Esa no jerarquización del dibujo y la escritura en cuanto actividades en cierto modo equivalentes concuerda con la afirmación, en la misma entrevista, de que sus primeras vocaciones fueron la pintura y el cine -"vocaciones superpuestas" a la de la escritura-, así como con su autodescripción como una suerte de cineasta por escrito -alguien que hace cine a través de la escritura, puesto que la timidez o las "dificultades" del medio uruguayo le habrían disuadido de intentar el cine propiamente dicho. ${ }^{14}$ Alguien, en otras palabras, que a partir de las "vocaciones superpuestas" del cine, el dibujo y la escritura, se ve movido a la invención de algo que vendría a ser una imposible mezcla de espectáculo masivo, cine experimental, humor gráfico y bizarra poesía.

6 Junto a la específica productividad de las escenas de "visión de la escritura", la textualidad levreriana es notable por la manera en que focaliza y deconstruye la imagen del escritor. La citada entrevista-cuestionario de Pablo Rocca se abre precisamente con unas palabras preliminares que plantean una aguda disociación entre la figura autorial y el yo no-escritural de Levrero :

El escritor es un ser misterioso que vive en mí y que no se superpone con mi yo, pero que tampoco le es completamente ajeno. Afinando un poco más la percepción, podría decir que el escritor se crea en el momento de escribir, por la confluencia del yo con otros estratos, núcleos o intereses del ser. Cuando yo respondo preguntas $\mathrm{u}$ opino por mi cuenta, sea de viva voz o por escrito, puedo asumir el rol del escritor, es decir, ponerme el disfraz o la máscara que me parece adecuada a esa función, pero no puedo responder ni opinar desde la función. [...] El escritor que se crea en el acto de escribir, concluido éste, se disuelve. El yo queda miserablemente solo frente al crítico y al público; de ahí la necesidad del disfraz o rol -que no debe confundirse con el escritor : a ése sólo se le puede encontrar en los textos literarios. ${ }^{15}$

El extrañamiento de la figura autorial que propone este pasaje recuerda el de un famoso texto borgiano -"Borges y yo" (1960). Pero donde Borges esboza en última instancia una inquietante indistinción entre el autor literario y el yo histórico -"no sé cuál de los dos escribe esta página"16-, así como una melancólica disolución de éste, inexorablemente absorbido por aquél -“Así mi vida es una fuga y todo lo pierdo y todo es del olvido, o del otro"17-, Levrero plantea una notable disminución de la imagen autorial en cuanto efímero disfraz o máscara evanescente del yo, o bien como función textual en cuya configuración intervendrían otros estratos de su ser (por eso no le sería del todo ajena) pero desde la cual nunca podría hablar el yo en cuanto sujeto de una enunciación no literaria. Su imagen de escritor tiene poco que ver entonces con la figura clásica de la autoría literaria -la figura horaciana del exegi monumentum aere perennius que reescribe el texto de Borges ${ }^{18}-$ : más bien sugiere una suerte de cruce entre el tema de la "teatralidad del rostro" en la narrativa de Felisberto Hernández (pienso en particular en un texto como "La envenenada") y la inestable figura del "escritor no-escritor" que recurre en la obra de otro notable imaginador excéntrico -el poeta, narrador y díscolo memorialista cubano Lorenzo García Vega. ${ }^{19}$

8 La entrevista-cuestionario de Pablo Rocca concluye con un irónico epílogo de Levrero que tematiza la tensa relación entre entrevistador y entrevistado -agudizada en este caso 
por la tenacidad investigadora (Levrero diría : "persecutoria") de aquél. El epílogo se abre con un caveat donde Levrero sugiere el posible carácter ficcional de sus respuestas -que al ser respuestas escritas implicarían un grado de premeditación y elaboración literaria no muy diferente del de la auto-entrevista "imaginaria" de El portero y el otro : "A lo largo de estas respuestas he sembrado algunas pistas falsas. Los críticos se parecen a los policías no sólo en su carácter represor (para bien o para mal), sino también en su carácter investigador" ${ }^{20}$ Lo interesante es cómo al hacerse visibles las tensiones que cruzan la relación entre el crítico y el autor, lo visual y lo escritural (así como las figuras del críticopolicía y del escritor-delincuente) se enlazan en un delirante bucle imagotextual -una suerte de proliferante anillo de Moebius entre lo que se ve y lo que se lee. En su rol de escurridizo o delictivo escritor, Levrero se despide de su policial perseguidor regalándole una última pista : las iniciales del nombre de su "compañerita de juegos en Peñarol" : M. S. A. M. ${ }^{21}$ Dilucidar si la pista es verdadera o falsa, como sugiere el autor con juguetona malicia, a todas luces importa menos que la vertiginosa serie de transposiciones entre la imagen y la letra a que da pie esa "pista" : como si una rara aptitud borgiana para el vértigo de las metalepsis deviniera pulsión iconotextual, ${ }^{22}$ una aceleración cómica de la facultad imaginativa por la que se desplazan las tecnologías visuales y las técnicas de la crítica literaria. o bien como si estuviéramos viendo una película pasada al doble o al triple de velocidad, o en cualquier caso algo que tendría la elástica mutabilidad de dibujos animados por escrito :

Si Pablo tiene oportunidad de hablar con ella, M. S. A. M. tal vez le cuente que ella tenía un gato llamado Bijou (o Biyú), y es posible que conserve alguna foto de ese gato. Observando la foto con lupa, Pablo podrá descubrir que en las manchas de su pelaje se insinúan unas formaciones que evocan algunas imágenes; vistas al microscopio, estas imágenes se vuelven completamente nítidas $\mathrm{y}$, en su conjunto, muestran puntualmente los hechos que luego aparecerían en mi novela La ciudad. Calculo que una vez publicado este importante descubrimiento de Pablo, un crítico radicado en U.S.A. encontrará la forma de hacerse con copias de la foto del gato, y las hará examinar con instrumentos, de mayor precisión, que hay allá. Así podrá descubrir que el gato no era tal, sino un hipopótamo, y que las imágenes impresas en la dura piel no son exactamente las de La ciudad (la estación de nafta, el gordo Giménez, Ana, el camión), sino letras ; estas letras, ordenadas convenientemente, permiten leer las obras completas de Edward George Bulwer, Lord Lytton (1803-1873), lo que dará origen a una pequeña monografía sobre la influencia de "Los ltimos días de Pompeya", de Bulwer-Lytton, en El lugar, de Mario Levrero. ${ }^{23}$

La productividad en la narrativa de Levrero de lo que he dado en llamar el "dibujo" de la escritura, a menudo ligado como hemos visto al deslinde de una reticente figura autorial, es complementaria a una específica visión de la escritura en cuanto trabajo del "dibujo de lo real”. Dos textos recogidos en el primero de los dos volúmenes de Irrupciones (2001) -la mencionada serie de columnas publicadas en la página cultural de la revista Posdataarticulan esa visión de manera explícita. De acuerdo con el primero de ellos, la escritura sería una manera de trabajar la "imagen del mundo" -el dibujo personal de la vida-, que nunca llega a coincidir con la realidad, y que es continuamente retrazado y reajustado ante las "irrupciones" más o menos inesperadas o azarosas de lo real :

Uno va armándose el mundo en que quiere, puede o acepta vivir, a partir de datos que va recibiendo desde que nace. Va armando un rompecabezas infinito, al que siempre se le puede agregar, y de hecho se le agrega, nuevas piezas, incluso entre 
dos piezas que parecían perfectamente ajustadas: parece que allí, justo allí, la imagen, o trozo de imagen, estaba completa ; pero viene otra pieza y calza entre esas otras dos tan ajustadas, calza y cambia la significación de ese trozo de mundo, tal vez del mundo entero -de ese mundo que nos hemos creado o nos vamos creando mientras vivimos.

Fuera de ese mundo creado, está todo lo demás. Lo que no conocemos, lo que no soportamos, lo que nos disgusta más allá del disgusto que podemos tolerar. Fuera de ese mundo que nos hemos creado para poder vivir, se halla el mundo real, incognoscible; el mundo que no era para nosotros.

La mujer que vino el otro día a casa a tratar de vender su mercadería había formado parte, hasta entonces, de ese mundo ajeno. Algo se alteró en mi mundo para que ella pudiera entrar. [...] hablo de una entrada en mi mundo como pieza de mi rompecabezas, forzando un dibujo. ${ }^{24}$

Para Levrero la ficción no sería tanto un género literario cuanto una suerte de constante antropológica de la que deriva una poética de la escritura anti-mimética. La ficción no se define aquí como mímesis en el sentido aristotélico del término, sino como re-trazado del "dibujo de la vida": lo que se opone a lo real en cuanto incognoscible, asimilando sus intempestivas irrupciones, para hacer la vida tolerable o vivible. La ficción es lo que se produce en el intervalo entre el dibujo de lo real y su siempre inminente descomposición y recomposición -la específica fricción que emerge entre dos piezas que no "calzan". Lo "real" no sería algo dado -algo que se podría reflejar o representar-, sino que se manifiesta siempre como irrupción/interrupción en lo conocido. La ficción levreriana podría describirse entonces como una sutil tela, una película de imágenes-palabras extraordinariamente sensible a las filtraciones luminosas o atroces de lo real como irrupción -a los descalces y desplazamientos del dibujo que nos llevan a una conciencia de la ficción.

11 Esta concepción de la ficción como trabajo de lo desconocido o incalculable que perturba nuestro "dibujo del mundo" se retoma en otra de las "irrupciones" incluidas en el mencionado volumen, en un texto que puede leerse como una suerte de fenomenología de la re-composición del "dibujo":

Cuando se inserta una nueva pieza cuya existencia no parecía posible o no se sospechaba, entre dos piezas contiguas de ese rompecabezas que es nuestra representación del mundo, algo parece ponerse a punto de estallar -la mente se resiste a incorporar de buenas a primeras esa nueva pieza imprevista, y por lo general no sabe cómo hacerlo ; para la mente, la aparición de esa nueva pieza es como la irrupción de una nueva dimensión en la realidad, y no sabe cómo manejarla. Después, la persistencia de esa pieza, la tangibilidad manifiesta de su presencia, hace que la mente vaya comprendiendo que el dibujo anterior que se formaba sobre la superficie del rompecabezas era un dibujo de aspecto coherente pero falso, y que ese dibujo debe ser cambiado por el otro que propone la superficie de esa nueva pieza.

Pero no es algo tan sencillo como esta forma de expresión que he imaginado, ya que pieza y dibujo y superficie son una misma y única cosa que no puedo representar de un modo más fiel..$^{25}$

12 Nuestro "dibujo del mundo" sería siempre una representación imperfecta e incompleta, en continua transformación y reajuste, como un puzzle que continuamente incorpora nuevas piezas -y "no se puede alterar un fragmento sin que se altere todo el conjunto". ${ }^{26}$ A partir de este planteamiento, la textualidad levreriana se propone como una específica forma de irrupción : como exploración de las fisuras entre las zonas de mundo "conocidas" -de la delgada línea que las separa "como una resquebrajadura en el cuadro de un paisaje". ${ }^{27}$ 
13 Una de las entradas de sus “Apuntes bonaerenses”, texto pseudo-diarístico incluido en El portero y el otro, propone una variante de la figura del "rompecabezas" que se vincula a una poética del dibujar sin modelo -y al fragmentario discurso amoroso con el que se compone la imagen de la mujer deseada:

La voy obteniendo por pedazos. Un sábado baja del avión, toma un taxi hasta casa, hacemos el amor, comemos, peleamos un poco o simplemente nos contamos algo, y se va. Cuando vuelve, dos o tres semanas más tarde, todo se repite pero nunca igual, porque nosotros nunca somos iguales a nosotros mismos.

Entre una visita y otra yo pienso en ella, trato de construirla, pero cada visita añade nuevos elementos que destruyen lo que estuve construyendo. Hay imágenes contradictorias, como dos piezas idénticas de un rompecabezas pero con distinto dibujo. No sé cual elegir para mi construcción. Luego se ve, en otra visita, que el rompecabezas era mucho más grande y que una de las dos piezas va en otro sector, en otra parte del dibujo. Pero no sé cual es el dibujo que tengo que armar. No hay modelos. $^{28}$

14 En cierto modo como estos fragmentos de discurso amoroso, el relato levreriano se arma como un rompecabezas cuyas piezas van esbozando un dibujo impredecible. En ese "inacabado" del dibujo reside el placer del texto - "sabe que si yo terminara de armar el dibujo, de construirla tal como es, me aburriría de ella, dejaría de amarla". ${ }^{29}$ Lo inacabado del dibujo es lo que permitiría seguir narrando, imaginando -amando- a partir de la lógica del "nunca ser tal como es" -toda vez que "nunca somos iguales a nosotros mismos". Lógica anti-mimética de lo bizarro, del desvío de la representación que hace emerger la ficción en lo que "no calza", en las fisuras de lo absurdo -lo que no es lo que debería ser o no encaja en una lógica preconcebida. De ahí que estos fragmentos de discurso amoroso deriven en un hilarante (a la vez que escalofriante) diálogo telefónico donde los amantes devienen clowns beckettianos, inmersos en la lógica corrupta de un inopinado idilio trans-sexual: "Cuando logro decirle que la amo o que la extraño, su respuesta puede ser, por ejemplo : 'y cómo andan sus cosas, doña Catalina', dicho con voz fría o por lo menos no con la voz que suele reservar para hablar conmigo. [...] En las escasas ocasiones en que estoy perfectamente lúcido y sobreaviso, respondo con humor: 'muy bien, Roberto' y vuelvo a mi tema [...]".30

15 La poética de la ficción anti-mimética que puede inferirse de estos textos -una poética de la ficción irruptiva - se explicita en una de las últimas piezas de la serie de Irrupciones. Levrero plantea ahí una crítica de la dicotomía realidad/imaginación que suele sustentar las poéticas realistas, lo que a su vez le sirve para redefinir la noción convencional de "realidad". Argumento central de esa crítica es la defensa de lo real de la imaginación, en la que pone un empeño equiparable al que dedica a afirmar lo incognoscible de la realidad como totalidad. La crítica adopta la forma de una carta a un innominado "amigo crítico" (no sabemos si real o ficticio), pero su auténtico destinatario es un crítico con nombre y apellido citado por su amigo, y que no es otro que Ángel Rama, probablemente el crítico uruguayo más influyente en las letras latinoamericanas del siglo XX :

"Hay una palabra ( =una actitud)" -le escribí, entonces, a mi amigo el crítico-“que es como una piedra que encuentro a cada rato en el camino de la lectura de tu ensayo : la palabra 'realidad', que no dice nada y que parecería decir mucho. Tal como la empleás (y como se emplea por ejemplo en las citas que hacés de Ángel Rama), supone un conocimiento cabal del significado de la palabra, que a mi juicio más bien debiera sustituirse por 'las cosas tal cual las percibo', o 'lo que yo creo la verdad de las cosas"'[subrayado del autor]. ${ }^{31}$ 
De hecho la carta (real o ficticia) funciona como una diferida réplica a la crítica que Rama le hiciera a la literatura de Levrero en términos de un "libertinaje imaginativo" que rehuiría la responsabilidad ante la "realidad social" de su tiempo. ${ }^{32}$ El carácter de contracrítica del texto de Levrero es patente cuando expone los límites de la noción de "realidad social" manejada por Rama : "Para el crítico que citás, la realidad es una 'realidad' social que no tiene en cuenta la física contemporánea ni se interesa por el comportamiento paradojal de la luz y de la materia-energía en general, ni muchas otras cosas existentes e incluso determinantes; $y$ la suya es una 'realidad' social armada desde el prejuicio ideológico, desde ciertas categoría de ideas preestablecidas". ${ }^{33}$ La contra-crítica de Levrero reivindica lo verdadero y aun lo realista del "libertinaje imaginativo" en cuanto escritura no ideológica -i.e. en cuanto aproximación asintótica y tangencial a lo verdadero de una realidad que nunca es posible conocer sino parcial o tendencialmente. Sería un modo de aproximación por proliferación fractal, no teleológica, que de hecho amplía (o al menos no obtura de antemano) las "puertas de la percepción", para decirlo con una vieja metáfora : $:^{34}$

"No entiendo por qué ustedes oponen realidad a imaginación, como si la imaginación estuviera fuera de la realidad, o si lo que sucede en la mente o en el espíritu no tuviera existencia 'real y efectiva', o fuera un ente 'no verdadero', es decir una mentira. [...] La imaginación forma parte de la realidad, si entendemos la realidad como 'lo existente'. Los productos de las operaciones de la imaginación también forman parte de la realidad, porque son existentes. Esa forma de dividir y oponer : realidad versus imaginación, da pie a que se formen bandos de quienes se ubican 'en la realidad', desde la cual juzgan a lo imaginario y lo analizan por medio de categorizaciones que se corresponden con categorías psiquiátricas. Se percibe esa diferencia entre realidad e imaginación como igual a 'verdad' y 'mentira', o 'salud' y 'enfermedad'". ${ }^{35}$

17 En su cuestionamiento de los modelos de realidad vigentes, la poética de la ficción levreriana indaga la compleja interrelación de los procesos perceptivos e imaginativos. Las ficciones de Levrero se conciben como artefactos explícitamente orientados a evitar la "versión ingenua y espontánea de la percepción" a la que se refiere el narrador (y parapsicólogo amateur) de su novela corta Fauna. ${ }^{36}$ Muchos de sus relatos y novelas funcionan como esas "ilusiones ópticas que aparecen en las revistas de entretenimientos" ${ }^{37}$ (a cuya invención, por cierto, se dedicó Levrero en más de una ocasión para ganarse la vida) y en particular como Kippfiguren -figuras anfibológicas, como aquel famoso dibujo de Wittgenstein que visto desde cierto ángulo es un pato y desde otro un conejo. ${ }^{38} \mathrm{La}$ escritura levreriana es notable por la manera en que trabaja las fisuras -las discontinuidades e interferencias - entre lo que con Wittgenstein llamaríamos el "ver continuo" y "el fulgurar de un aspecto". ${ }^{39}$ Ello es patente en esta novela, que explora el juego de oscilaciones entre el deseo, la percepción, el recuerdo y el sueño en torno a la imagen de la "doble y única mujer" Flora/Fauna (en principio dos hermanas, que en el curso de la narración se revelan como avatares de una misma mujer); o en el fragmento 13 de "Confusiones cotidianas", que plantea una suerte de "indecidibilidad" de la imagen entre el deseo, la percepción y el ensueño (una mujer avistada en la playa, por un momento, un "tronco retorcido de árbol, trabajado por el agua", después). ${ }^{40}$ Este texto, como varias piezas de la serie de Irrupciones, exploran el intervalo entre la imagen y su sentido, produciendo un efecto de diferimiento entre lo percibido y su "explicación" -un margen de suspensión del juicio por el que emergen repentinos extrañamientos del espacio doméstico o urbano, fulgurantes microficciones cotidianas. Los textos de esta serie -entre los que ocupan un lugar destacado las novelas "gemelas" Fauna y Desplazamientos - tematizan el deseo de una imagen como móvil de la ficción, y trabajan la imagen como Kippfigur : figura parpadeante entre la materialización de un deseo y su 
continua demistificación y recomposición, entre la aparición de la imagen y sus desmontajes y reposicionamientos crítico-ficcionales.

La reivindicación levreriana de lo real de las "operaciones de la imaginación" tiene una rica vertiente en la exploración de la específica parcela de realidad que concierne al mundo de los sueños. Comentando la citada carta al "amigo crítico", observa: "Hay también quienes oponen 'realidad' a 'sueño', siendo que lo opuesto a sueño es, por lógica, 'vigilia'. El sueño tiene su realidad, su verdad que, aunque distinta de la realidad de la vigilia, no por ello es menos 'real', menos verdadera". ${ }^{41} \mathrm{Y}$ en otra de sus "Irrupciones", que adopta la forma del comentario de un sueño reciente, afirma :

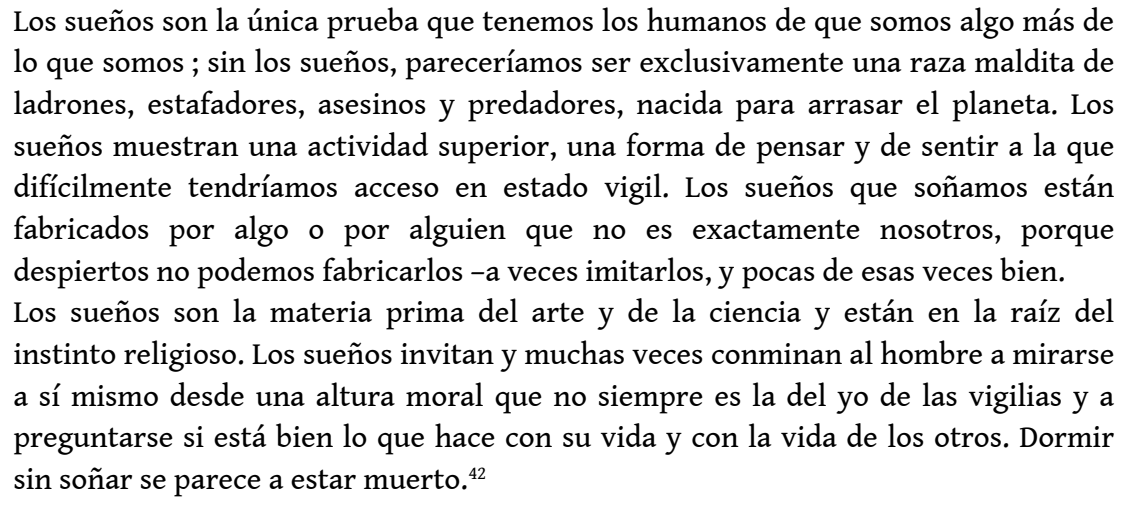

19 A la luz de esta encendida apología no extrañará que esta "irrupción" empiece por rescatar una frase extraviada en el proceso de publicación de otro texto suyo aparecido en la revista Posdata -donde decía "nada más que un sueño" debería decir : "nada menos que un sueño; nada menos" [subrayado del autor]. ${ }^{43}$ Nada menos que un sueño: la frase bien podría ser un emblema de la escritura de Levrero. En la centralidad que éste otorga a los sueños en la creación artística y científica es notoria la afinidad con las prácticas del surrealismo. Con esta salvedad: en la articulación de una literatura imaginativa que se propone como imitación de lo real de los sueños en cierto modo se redefine la tradición de las vanguardias a la vez que la tradición de la novela realista. Levrero se refiere a menudo a sus relatos y novelas como mecanismos de "transliteración" de sueños, en lo que cabe ver otro nivel de enlace de lo visual y lo verbal que moviliza profundas vetas de su escritura. ${ }^{44}$ Ello es particularmente relevante si pensamos en las operaciones de condensación y desplazamiento que intervienen en la producción de imágenes oníricas a partir de frases o fragmentos de discurso de la vigilia. Operaciones estudiadas en detalle por las investigaciones psicoanalíticas de Sigmund Freud, ${ }^{45}$ cuya Traumdeutung (1900) constituye como es sabido un insoslayable pre-texto del surrealismo -así como tambien, en no poca medida, de las ficciones levrerianas. Así lo sugiere al menos esta "irrupción", que remeda el procedimiento del análisis freudiano en la interpretación que propone Levrero de un sueño reciente (un sueño en que se ve a sí mismo durmiendo junto a una mona) como "trans-imaginación" o re-composición visual de la expresión "dormir la mona" -frase que condensaría el sentimiento de culpa con el que se acostó la noche en que tuvo el sueño, tras una sesión de "borrachera" digital ante la hipnótica pantalla de la computadora. 
20 De hecho la escritura de Levrero se da en gran medida como trans-imaginación (como recomposición narrativa) de las visiones de sus sueños, según un específico procedimiento de "traducción intersemiótica" o de "transcreación" icono-gráfica (para evocar las teorías de la traducción de Roman Jakobson y de Haroldo de Campos) ${ }^{46}$ que seguramente no es ajeno al intenso carácter visionario de sus ficciones. Ello implicaría otra dimensión de la ek-frasis, de lo que salta de la frase para hacer visible otro "cuadro", otro plano de figuración extratextual. Pues en las ficciones levrerianas tan decisiva es la ékfrasis "tecnomediática" que apela al régimen simulacional de la cultura global de masas del capitalismo tardío -cuestión bien estudiada por Jesús Montoya Juárez ${ }^{47}$ - como lo que podríamos llamar la ékfrasis "onírica" : lo que salta de las palabras remontándolas a sus orígenes, vale decir, llevándolas a contracorriente hacia las imágenes de los sueños de donde proceden. ${ }^{48}$

21 Sueños que, por lo demás, no son inmunes al imaginario de la cultura de los medios contemporánea, como lo evidencia una de las últimas "Irrupciones" (la penúltima del segundo volumen). En este texto Levrero se demora en una reflexión sobre la muerte que hilvana la imagen de un sueño recurrente (la imagen de una "vieja espantosa" que lo vuelve a visitar hasta que despierta entre sudores fríos) con el imaginario de la cultura visual de masas y las nuevas tecnologías de la información. La descripción ekfrástica de una tira cómica de Snoopy, cuyo paralizador miedo a la muerte es un correlato del que invade al impenitente soñador Levrero (crecientemente preocupado por la vejez en las piezas finales de Irrupciones), se enlaza con el imaginario tecnomediático a través de la metáfora del hardware/software para plantear la oposición entre la evanescencia o "reprogramabilidad" del yo (programa activado a partir de "archivos sueltos") y la inmortalidad del ser (el "ácido nucleico" que se transformará en otros seres tras la desaparición del yo) :

“¡Soy demasiado joven para morir!”, “Soy demasiado bueno para morir!”, pensaba, muy triste, el perro Snoopy; su casilla estaba amenazada por un enorme carámbano, estalactita de hielo que podía desprenderse en cualquier momento, mientras Charlie Brown y Linus le gritaban que saliera de allí, que corriera. El pobre Snoopy estaba demasiado aterrado para moverse. Y su siguiente reflexión era: “ $¡$ Soy demasiado yo para morir !"

Y ése es el asunto : el yo. El yo es lo único que muere, el yo es esa ficción utilitaria que el ser humano necesitó crear para sobrevivir. Pero el ser no muere -ese ser que es ácido nucleico, y que es mis padres y mis hijos y mis amigos y todos los perros y todas las hormigas y todas las plantas y... [...] El problema de la muerte es el problema del yo. [...] por eso tal vez aceptamos ser masificados por la publicidad, por los líderes, por las formas infinitas del trance y del olvido de la vida que nos ofrecen, cada día más, esos oscuros organizadores de nuestra esclavitud.

Cuando llega la hora de morir, si nuestro yo está disuelto previamente, no hay muerte. Podemos disolverlo voluntariamente, por medio de una sabiduría que ciertos trabajos permiten alcanzar; disolverlo y crearlo voluntariamente, como se carga un programa en la computadora a partir de unos archivos sueltos. También podemos hacer como la mayoría, y dejar que otros disuelvan nuestro yo a su antojo mientras, de paso, construyen sus pilas de moneditas; lástima que de esa forma habremos pasado vanamente, sin haber siquiera atinado a soñar con nuestro real, positivo, verdadero Ser. ${ }^{49}$

22 La crítica de la publicidad "masificante" (una de las fobias predilectas de Levrero) recurre a lo largo de la serie de Irrupciones. En cuanto alienación del yo que haría superfluo el miedo a la muerte, el efecto masificador de la publicidad estaría íntimamente ligado tanto al auge de los fascismos y populismos históricos como a la actual configuración de la 
cultura global de masas -eso que Antonio Méndez Rubio llama "fascismo de baja intensidad". ${ }^{50}$ Lo interesante aquí es cómo la crítica de esa configuración cultural "esclavizante" da paso a la aparición de un modo de imaginación del propio ser vinculado al sueño y a la creación artística que se opone en cuanto "invención verdadera" a la disolución alienante del individuo pre-programada por la "publicidad masificante", así como a la construcción del yo como ficción de supervivencia ligada a las prácticas de la vida cotidiana. Sería un ejemplo de cómo la escritura-sueño levreriana -la escritura como imitación de los sueños- se propone como "transcreación" intersemiótica de las imágenes oníricas y como ékfrasis intermedial de la visualidad de masas del capitalismo tardío ${ }^{51}$-esto es, como algo que, lejos de lo que Rama criticara bajo el rubro del "libertinaje imaginativo", se concibe como exploración de lo más verdadero del ser humano en tanto que ser soñante-imaginante en la era de la información y de lo que con Vilém Flusser llamaríamos el "universo de las imágenes técnicas". ${ }^{52}$

La escritura de Levrero implica siempre alguna forma de irrupción y desplazamiento iconotextual. Consideremos dos ejemplos : el primero, un texto incluido en el segundo volumen de Irrupciones, propone una reescritura de la imagen central de su novela Desplazamientos (1987). El texto plantea un "corte visual" -"como en una fotografía"- por el que la imagen se trabaja en clave microscópica, exasperando el gesto ekfrástico de "hacer ver" por medio de las palabras. De hecho, esa reescritura remeda en su planteamiento un ejercicio escolar de descripción, como si se tratara de un examen o una prueba de redacción que el autor se impone a sí mismo : "Describa en no menos de quinientas palabras y de un modo objetivo la que usted considere imagen principal de la novela titulada 'Desplazamientos"'.53 El alumno perverso Levrero procede a partir de ahí a una "transcreación" de su propio texto : una suerte de trans-imaginación de su escena central que opera según un principio de geometrización de sus actantes narrativos y sus zonas erógenas, semejante al que ensaya en la "Novela geométrica" de El portero y el otro -a su vez un relato que evoca una de las primeras invenciones de Felisberto Hernández: "Genealogía", un experimento narrativo con la visualidad cubista incluido en Libro sin tapas (1929). La imagen central en torno a la que gira obsesivamente la novela -la escena del encuentro sexual entre el narrador-protagonista y una mujer que le inspira un incontenible deseo- se reescribe paródicamente en una suerte de pastiche de discurso pseudo-matemático y psicoanalítico en virtud del cual el narrador pasa a ser el "sujeto irruptor (S)" y la mujer deseada el "objeto predominante (OP)". Análogamente, la fascinación que la imagen del cuerpo semidesnudo de ésta ejerce sobre aquél deviene una especie de cuadro abstracto -un laberíntico juego de rectas, figuras geométricas y bisectrices (un poco a la manera del Desnudo bajando una escalera de Duchamp) que proponen una suerte de delectatio morosa en lo inimaginable de la "lujuria de ver" :54

Para este trabajo nos hemos propuesto detener el movimiento como en una fotografía, y mostrar, como en un corte, el momento de una percepción muy intensa del sujeto irruptor (s), seleccionando para ello un instante del primer encuentro de S con lo que hemos dado en llamar "objeto predominante", es decir, cuando ambos se reúnen, muy próximos entre sí, en las inmediaciones del punto D por un desplazamiento del objeto predominante (OP) hacia S, a lo largo del segmento de recta imaginario DE, partiendo del punto $\mathrm{E}$ y moviéndose a lo largo de prácticamente todo el segmento. [...]

Al detener el movimiento y fijar de este modo la escena, ubicándonos 
imaginariamente en el punto de vista de $\mathrm{S}$, podemos comprobar que : el campo visual, reducido por el acercamiento del OP y por la inmovilidad de los ojos de S, a quien hemos detenido en su desplazamiento, abarca en su conjunto una superficie rectangular que la cercanía de las paredes del pasillo y las sombras producto de una iluminación escasa estrechan hasta convertirla en un cuadrado [...] El foco de atención visual, punto de máxima nitidez perceptiva, debe situarse en la confluencia de una línea vertical difusa, en la instancia en que comienza a bifurcarse o insinúa el comienzo de una bifurcación hacia los márgenes inferior izquierdo e inferior derecho del cuadrado, cortada a su vez por una línea horizontal más aparente, ligeramente curva. El foco de atención está centrado entonces en un pequeño triángulo o más exactamente en la insinuación de un pequeño triángulo con un muy rico juego de luces y sombras, y estas líneas son interpretadas como el nacimiento de los pechos que, apretados por el sostén (correspondiente a la línea horizontal más aparente, ligeramente curva) tienden sin embargo al mismo tiempo a separarse (inicio o insinuación de esa bifurcación señalada, frustrada por la línea horizontal) a influjo de su propia naturaleza elástica. ${ }^{55}$

En cierto modo lo que se parodia aquí es el afán "objetivo" no sólo de controlar el poder de fascinación de la imagen sino de fijar su potencialidad de dispersión semiótica por medio de un hiperbólico discurso analítico. De paso, se remeda (sacándolo de quicio) el principio compositivo del desplazamiento a partir del cual se construye la novela, donde la imagen obsesionante de la mujer deseada se re-traza a través de una proliferación fractal de secuencias narrativas que se interrumpen y recomienzan solapándose entre sí, retomando la imagen cada vez desde un nuevo ángulo, lo que da pie a nuevas series de desplazamientos y bifurcaciones narrativas que se suceden indefinidamente formando una compleja figura topológica.

El segundo ejemplo que quiero destacar es un "iconotexto" en el sentido de Nerlich -una "irrupción" que incluye un dibujo generado por computadora y su interpretación (vid. figura 1) : "Este dibujo irrumpió en mi computadora. No es la primera vez que me sucede, ni me sucedió exclusivamente en computadoras, pero hacía tiempo que no me sucedía, y me sorprendió; yo sólo estaba tratando de probar un programa nuevo de dibujo que había instalado. Y dibujé, o se me dibujó, esto". ${ }^{56}$ Este texto es interesante por la oposición que plantea entre el discurso y el dibujo (en términos lacanianos diríamos: entre lo simbólico y lo imaginario) ${ }^{57}$ en cuanto aquello que va "un poco más allá de los conceptos". ${ }^{58}$ La crítica levreriana de la dimensión lógico-conceptual de las palabras -y la visión del dibujo como línea de fuga o "más allá" de lo simbólico- ${ }^{59}$ recuerda la desconfianza de Felisberto Hernández hacia la "conciencia" y las explicaciones racionales en su "Explicación falsa de mis cuentos" (1955). ${ }^{60}$ En cierto modo como la "planta" del cuento de Felisberto, ${ }^{61}$ el dibujo levreriano se da como algo a medio camino entre la voluntad consciente de creación y la irrupción heterónoma -en este caso, no es tanto algo que dibujó cuanto algo que se le dibujó. De ahí que más adelante afirme que tanto el dibujar como el escribir es algo que siempre le sale "de chiripa" - "todo lo mío es chiripa, tanto lo que dibujo como lo que escribo"62-, si bien cabe sugerir que, como en Felisberto, sus textos escenifican una continua dialéctica "en suspenso" entre lo espontáneo o inconsciente y lo artísticamente calculado.

De ahí, también, la diferencia que plantea entre "lo que se ve" y lo que "está dibujado" vale decir: entre lo que se percibe y lo que se entiende: la imagen subordinada o adherida a un determinado régimen de sentido. Lo dibujado sería siempre lo que "no se sabe", lo que está más allá o más acá de la explicación :

Sin embargo todo esto que se ve, es lo que se ve, y no lo que está dibujado. Lo que está dibujado no se sabe qué es ; nadie lo sabrá, nunca, del todo. Por eso tenía que 
dibujar en lugar de escribir, creo yo : para ir un poco más allá de las palabras, un poco más allá de los conceptos, para intentar poner a la vista algo que no es accesible a las palabras ni a los conceptos. ${ }^{63}$ de "en lugar de" así como de "lugar de" -lugar de escribir (en lugar de escribir). Es decir, el dibujar no sólo sería algo que se opondría al escribir sino un específico modo de escritura ligado a un "dejar de escribir" -un modo de visualizar la escritura en la producción de su abandono, que Levrero llevará a su expresión más extrema en El discurso vacío (1996), en el proyecto "terapeútico" de reducir la escritura al dibujo de su trazado (a la operación manual de la inscripción caligráfica, de hacer "buena letra"), vaciándola de todo discurso o sentido trascendente. Otra variante de ese modo de "no-escritura" -otra variante tecnomediática, proporcionada por un procesador de textos- es la que describe al final de otro texto incluido en Irrupciones I : escribir tachando lo que se escribe al mismo tiempo que se escribe (de modo que al describir el procedimiento lo pone en práctica, haciendo visible la tachadura y la letra que va tachando) : "Encontré en el procesador de textos un botón que, al oprimirlo, permite ir tachando todo lo que se escribe. Lo interesante de este procedimiento es que permite ir tachando al mismo tiempo que se escribe. Me siento tentado de seguir escribiendo así siempre". ${ }^{64}$

El escribir "dejando de escribir" es un gesto que tiene múltiples manifestaciones en la narrativa de Levrero. Lo encontramos en los frecuentes momentos de abandono o reducción al absurdo de la dimensión lógico-conceptual de la escritura -momentos que introducen un principio de deriva y extrañamiento semiótico. Así por ejemplo en un texto como "Confusiones cotidianas", incluido en El portero y el otro, un principio de proliferación fractal paronomásica visibiliza de manera aberrante la letra en cuanto significante desacoplado de su "máscara" de significado : "Xernández se quitó la máscara de Xonzález, con una carcajada feroz. Sin embargo, la reunión no pareció desconcertarse. Xutiérrez se quitó la máscara de Ximénez, Xérez la de Xópez, Xonzález la de Xérez, Xópez la de Xutiérrez y Ximénez la de Xernández, y así prosiguieron deliberando y la propuesta inicial de Xernández fue desde luego derrotada". ${ }^{65}$ De hecho este relato, como muchos otros de Levrero, abunda en visualizaciones textuales bizarras : el relato se produce por montaje de "metaimágenes", ${ }^{66}$ donde lo que ante todo se hace visible es el tropo, la función poética, las instancias narrativas y la autoconciencia textual. El fragmento que precede al pasaje citado hace repentinamente visible la mirada del lector, lo que produce un enceguecimiento -un vacío en la página que interrumpe la frase y el relato : "Los ojos que recorrían el texto esperando una continuación de la anécdota," (lo que sigue después de la coma es un espacio en blanco y el comienzo del siguiente fragmento, arriba citado). ${ }^{67}$ Levrero dibuja aquí la imagen de una mirada que lee, produciendo un cortocircuito, un colapso de la lectura, así como en El discurso vacío suspende indefinidamente la escritura (sosteniéndola funambulescamente a lo largo de más de cien páginas) en el imposible dibujo de un escribir reducido a la materialidad de la (buena) letra -una letra exdiscursiva o para-semiótica. El cultivo levreriano del "dibujo" de la escritura es un arte de los dibujos imposibles, que por momentos se propone el bizarro objetivo de "escribir mal" -un cierto ideal de ilegibilidad como salida de la "despiadada" coherencia del discurso: 68

Quiero aflojar por un momento la tensión de estar buscando la palabra justa, no exacta pero justa, esa despiadada desviación casi diría profesional, si lo mío fuera una profesión ; la palabra justa y la coherencia del discurso, un conjunto armonioso que el lector debe recibir sin darse cuenta del esfuerzo que lo sustenta. Estoy tratando de escribir mal, de permitirme incoherencias y faltas de ortografía, pero 
sólo he conseguido torpezas de tipiado que me he apresurado a corregir, porque no es lo que pretendía. ${ }^{69}$ dibujo generado por computadora. En esta "irrupción" es significativa la lectura del dibujo que ofrece Levrero en cuanto "autorretrato" -en cuanto esquema o "autorradiografía" de su alma, que lejanamente recuerda el trazo barroco de los diagramas lacanianos :

Por mi parte, desde un primer momento sentí que ese dibujo era una especie de autorretrato, o más bien autorradiografía. Mi ser profundo acusando una herida. Lo que veo es, de cualquier manera, alguien que se tapa la cara para no ver algo, pero el ojo se hace más visible que la mano, y la herida, ese rojo que no se quiere ver, se hace más visible que el ojo. ${ }^{70}$

En esta coreografía "en escorzo" del ojo, la mano y la herida, Levrero se autorretrata como sujeto determinado por el gesto de no querer ver y por la obscena visibilidad de eso que no se quiere ver -el propio ojo que mira, más visible que la mano que lo "tapa". En otras palabras : en el gesto de diferir la visión, eso que trataría de re-cubrir la mano que escribe o dibuja, lo que se hace indeciblemente visible es la "herida" de la autoconciencia -el ojo, ese "rojo que no se quiere ver". En cierto modo, este paradigma de "autorradiografía obscena" recorre de principio a fin la escritura de Levrero. Toda su obra narrativa -no sólo la que declara una más explícita vocación autobiográfica (las obras de la última época, desde los "Apuntes bonaerenses" y el "Diario de un canalla", incluidos en El portero y el otro, a El discurso vacío y la póstuma La novela luminosa) sino también la brillante serie de novelas y relatos que escribió a partir de su seminal "Trilogía involuntaria" - se diría orientada a la producción de una "autorradiografía" imagotextual que oscila entre el gesto de desplazar lo que no se quiere ver (las irrupciones más o menos perturbadoras de la imprevisible realidad) y la inscripción de la herida de lo real (la herida de la auto-conciencia) : entre lo que se ve y lo que se dibuja, entre lo que se esboza a través de palabras y conceptos y lo que "no se sabe lo que es" -entre el "arabesco" del cálculo artístico y lo que irrumpe como soberano capricho de la imaginación..$^{71}$ Como en Felisberto, en Levrero la "lujuria de ver" implica ante todo lo perverso o lo obsceno de la reflexión sobre la propia mirada, y de la escritura que se genera en esa ex-posición del ojo que mira. Ex-posición del ojo que mira: vale decir, lo que queda expuesto y lo que abandona su lugar y continuamente se desplaza a otra parte.

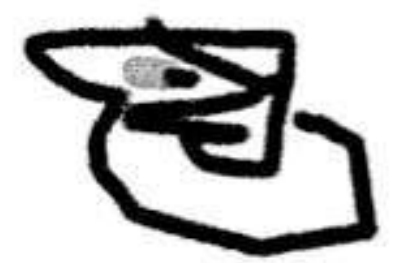

Fig. 1. Mario Levrero, Irrupciones II, p. 69. 


\section{BIBLIOGRAFÍA}

Bibliografía

Bachmann-Medick, Doris. Cultural Turns. Neuorientierungen in den Kulturwissenschaften, Reinbek bei Hamburg : Rowohlt, 2007.

Barthes, Roland. "La libertad de trazar", en El susurro del lenguaje, Barcelona : Paidós, 2009, pp. 69-72.

Benjamin, Walter. Das Passagen-Werk. Gesammelte Schriften I, ed. de Rolf Tiedemann, Frankfurt am Main : Suhrkamp, 1991.

Blake, William. The Marriage of Heaven and Hell. Boston, John W. Luce \& Co, 1906. <http:// www.gutenberg.org/files/45315/45315-h/45315-h.htm>

Borges, Jorge Luis. “Borges y yo”, en Obras completas, vol. 2, Buenos Aires : Emecé, 1989, p. 186.

De Campos, Haroldo. "Da tradução como criação e como critica”, en Metalinguagem : ensaios de teoria e crítica litéraria, Rio de Janeiro : Vozes, 1967, pp. 21-38.

De Rosso, Ezequiel (ed.). La máquina de pensar en Mario : ensayos sobre la obra de Levrero, Buenos Aires : Eterna Cadencia, 2013.

Díaz, José Pedro. "Del inextinguible romanticismo : la imaginación de Mario Levrero", en La máquina de pensar en Mario : ensayos sobre la obra de Levrero, ed. de Ezequiel de Rosso, Buenos Aires : Eterna Cadencia, 2013, pp. 21-26.

Flusser, Vilém. $O$ universo das imagens técnicas : elogio da superficialidade, São Paulo : Annablume, 2008.

Foucault, Michel. Las palabras y las cosas : una arqueología de las ciencias humanas, Madrid : Siglo XXI, 1995.

Freud, Sigmund. La interpretación de los sueños, Madrid : Alianza Editorial, 1966.

García Vega, Lorenzo. El oficio de perder, México : Benemérita Universidad Autónoma de Puebla, 2004.

Garfinkle, David y Richard Garfinkle. El universo en tres pasos : del sol a los agujeros negros y el misterio de la materia oscura, Barcelona : Crítica, 2010.

Hernández, Felisberto. "Explicación falsa de mis cuentos". Obras completas, vol. 2, Madrid : Siglo XXI, 1997, pp. 175-176.

Hernández, Felisberto, "Libro sin tapas”, Obras completas, vol. 1, Madrid : Siglo XXI, pp. 34-36.

Hernández, Felisberto, "La envenenada", Obras completas, vol. 1, Madrid : Siglo XXI, pp. 69-79.

Hernández, Felisberto, "El acomodador", Obras completas, vol. 2, Madrid : Siglo XXI, pp. 75-92.

Horacio Flaco, Quinto. Odas, Buenos Aires : Losada, 2005.

Jakobson, Roman. “En torno a los aspectos lingüísticos de la traducción”, en Ensayos de lingüística general, Barcelona : Seix Barral, 1981, pp. 67-77. 
Jost, François. “Des vertus heuristiques de l'intermédialité”, en Intermedialités 5 (2005), pp. 109-119.

Lacan, Jacques. El seminario. Libro 11. Los cuatro conceptos fundamentals del psicoanálisis. 1964, Buenos Aires : Paidós, 1997.

Levrero, Mario. El portero y el otro, Montevideo : Editorial Arca, 1992.

Levrero, Mario, Fauna / Desplazamientos, Buenos Aires : Ediciones de la Flor, 1987.

Levrero, Mario, Todo el tiempo : relatos, Montevideo : Ediciones de la Banda Oriental, 1982.

Levrero, Mario, Irrupciones, Vols. I y II, Montevideo : Cauce, 2001.

Levrero, Mario, El discurso vacío (novela), Montevideo : Ediciones Trilce, 1996.

Levrero, Mario, La novela luminosa, Montevideo : Alfaguara, 2005.

Levrero, Mario, Trilogía involuntaria. La ciudad. El lugar. París. Barcelona : Debolsillo, 2008.

Levrero, Mario, Santo Varón, Buenos Aires : Ediciones de la Flor, 1986.

Levrero, Mario, Los profesionales, Buenos Aires : Punto Sur, 1988.

Levrero, Mario, El llanero solitario, en Tinta, nำ 1-3, Rosario, 1979.

Méndez Rubio, Antonio. (FBI) Fascismo de baja intensidad, Santander : La Vorágine, 2015.

Mitchell, William. Teoría de la imagen : ensayos sobre representación verbal y visual,

Madrid : Akal, 2009.

Montaldo, Graciela. “La culpa de escribir : La novela luminosa de Mario Levrero", en Ínsula. Revista de letras y ciencias humanas, 777 (2011), pp. 26-29.

Montoya Juárez, Jesús. Mario Levrero para armar : Jorge Varlota y el libertinaje imaginativo, Montevideo : Ediciones Trilce, 2013.

Nerlich, Michael. "Qu'est-ce un iconotexte ? Réflexions sur le rapport text-image photographique dans 'La femme se découvre' d'Evelyne Sinnassamy”, en Iconotextes, ed. de Alain Montandon, Paris : Ophrys, pp. 255-302.

Premat, Julio. Héroes sin atributos : figuras de autor en la literatura argentina, Buenos Aires : FCE, 2009.

Prieto, Julio. La escritura errante : ilegibilidad y políticas del estilo en Latinoamérica, Madrid/Frankfurt am Main : Iberoamericana-Vervuert, 2015.

Prieto, Julio, Desencuadernados : vanguardias excéntricas en el Río de la Plata, Rosario : Beatriz Viterbo, 2002

Rajewsky, Irina. Intermedialität, Tübingen/Basel : A. Francke, 2002.

Rama, Ángel. La generación crítica : 1939-1969. I Panoramas, Montevideo : Editorial Arca, 1972.

Reggiani, Federico. "La historieta luminosa", en Hablando del asunto.com.ar, 19 de junio de 2009 $<$ http :criptahda.matiasf.com.ar/2009/06/levrero-historietista>

Rorty, Richard. The Linguistic Turn : Recent Essays in Philosophical Method, Chicago : University of Chicago Press, 1967.

Silva Olazábal, Pablo. Conversaciones con Mario Levrero, Montevideo : Ediciones Trilce, 2008.

Schlegel, Friedrich. Kritische Friedrich Schlegel Ausgabe, vol. XVI, ed. de Ernst Behler, Munich :

Ferdinand Schöningh, 1956. 
Schlegel, Friedrich, Literarische Notizen, 1797-1801, ed. de Hans Eichner, Berlín : Ullstein, 1980.

Steimberg, Oscar. "Para un comienzo de descripción de las historietas de Levrero", en La máquina de pensar en Mario : ensayos sobre la obra de Levrero, ed. de Ezequiel De Grosso, Buenos Aires : Eterna Cadencia, 2013, pp. 127-139.

Wagner, Peter (ed.). Icons - Text - Iconotexts. Essays on Ekphrasis and Intermediality, Berlin : de Gruyter, 1996.

Wittgenstein, Ludwig. Investigaciones filosóficas, Barcelona : Crítica, 2004.

\section{NOTAS}

1. M. Levrero, El portero y el otro, Montevideo : Editorial Arca, 1992, p. 181.

2. L. Wittgenstein, Investigaciones filosóficas, Barcelona : Crítica, 2004, p. 455.

3. W. Mitchell, Teoría de la imagen : ensayos sobre representación verbal y visual, Madrid: Akal, 2009, pp.19-38. Véase también, sobre la cuestión del cambio de paradigma cultural, D. BachmannMedick, Cultural Turns: Neuorientierungen in den Kulturwissenschaften, Reinbek bei Hamburg: Rowohlt, 2007.

4. Sobre el giro lingüístico en la filosofía, véase R. Rorty, The Linguistic Turn: Recent Essays in Philosophical Method, Chicago : University of Chicago Press, 1967.

5. Para esta noción véase J. Premat, Héroes sin atributos: figuras de autor en la literatura argentina, Buenos Aires : FCE, 2009.

6. Sobre la noción de ex-centricidad en el campo cultural rioplatense véase mi ensayo Desencuadernados : vanguardias excéntricas en el Río de la Plata, Rosario : Beatriz Viterbo, 2002.

7. La vertiente gráfica de su obra incluye las historietas El llanero solitario (1979), Santo Varón (1986) y Los profesionales (1987) - las dos últimas, realizadas en colaboración con el dibujante Lizán-, y los dibujos y experimentos misceláneos contenidos en sus cuadernos, en gran parte inéditos. En el Archivo Levrero de la SADIL se conservan dieciséis cuadernos compuestos entre 1967 y 1969 titulados Álbumes y Cuadernos del infierno. Jesús Montoya Juárez los describe así : "Se trata de documentos encuadernados en forma artesanal ideados para circular entre los amigos, miembros de la 'cofradía' o de la 'logia' levreriana" (Mario Levrero para armar : Jorge Varlotta y el libertinaje imaginativo, Montevideo: Trilce, 2013, pp.41-42). Uno de los miembros de la "logia levreriana", el poeta y artista plástico uruguayo Clemente Padín, refiere la siguiente anécdota a propósito de la inquietud pictórica de Jorge Mario Varlotta Levrero : "En una de las paredes de la pieza había escrachado comida y diferentes cosas que habían manchado la pared [...] después vi obras vinculadas al punk en los ochenta, cuando estuve en Berlín, que eran muy parecidas a lo que vi en su casa [...] Yo creo que Varlotta nunca conoció nada de eso [...] pero me pareció después una anticipación, cierto informalismo pictórico" (J. Montoya Juárez, op. cit., p. 42). Otros proyectos inéditos conservados en el citado archivo incluyen el extenso cómic "De los elefantes y sus aconteceres", la serie "Las aventuras del ingeniero Strudel" y el conjunto de ilustraciones numeradas "La nueva lógica". Para una aproximación a esta vertiente de la obra de Levrero, véanse los trabajos de Óscar Steimberg, Federico Reggiani y Jesús Montoya Juárez incluidos en la bibliografía.

8. M. Levrero, Irrupciones I, Montevideo : Cauce Editorial, 2001, p. 33.

9. Ibid, p. 35.

10. R. Barthes, El susurro del lenguaje, Barcelona : Paidós, 2009 : 69-72.

11. Irrupciones I, p. 46.

12. E. De Rosso (ed.), La máquina de pensar en Mario: ensayos sobre la obra de Levrero, Buenos Aires: Eterna Cadencia, 2013, p. 94. La confesión se encuentra en una notable entrevista que tiene algo 
de experimento : se trata de un cuestionario remitido por correo para ser respondido por escrito y cuyo autor, Pablo Rocca, optó por no conocer personalmente al entrevistado.

13. Ibid, p. 95.

14. Ibid, p. 94.

15. Ibid, p. 88.

16. J. L. Borges, Obras completas II, Buenos Aires : Emecé, 1989, p. 186.

17. Ibid, p. 186.

18. Horacio, Carmina III 30.

19. En cuanto a la figura del "escritor no-escritor" véase en particular la autobiografía poética de Lorenzo García Vega, El oficio de perder, México : Benemérita Universidad Autónoma de Puebla, 2004.

20. De Rosso, op. cit., p. 110.

21. Esta figura es trabajada ficcionalmente en su relato "La cinta de Moebius", donde aparece con los nombres de Susana/Marisa. Véase M. Levrero, Todo el tiempo : relatos, Montevideo : Ediciones de la Banda Oriental, 1982, pp. 41-81.

22. Michael Nerlich define el concepto de "iconotexto" como una "unidad dialógica, no ilustrativa" entre imagen y texto que se daría en una determinada obra (Iconotextes, ed. de Alain Montandon, Paris : Ophrys, pp. 255-302). Más allá de esta definición, en este ensayo considero las relaciones iconotextuales como un modo específico de intertextualidad que atañe al bucle interminable por el que, para decirlo con Michel Foucault, "la mirada y el lenguaje se entrecruzan al infinito" (Las palabras y las cosas, Madrid: Siglo XXI, 1995, p. 47).

23. Ibid, pp. 110-111.

24. Op. cit., pp. 30-31.

25. Ibid, pp. 66-67.

26. Ibid, p. 67.

27. Ibid, p. 66.

28. M. Levrero, El portero y el otro, pp. 119-120.

29. Ibid, p. 120.

30. Ibid, p. 121.

31. M. Levrero, op. cit., p. 64.

32. A. Rama, La generación crítica: 1939-1969. I Panoramas, Montevideo: Editorial Arca, 1972, pp. 244-45.

33. M. Levrero, op.cit., pp.110-111. El efecto de ampliación de lo real producido por el libre ejercicio de la imaginación que vindica la contra-crítica de Levrero recuerda una observación de Albert Einstein: “Tengo de artista lo suficiente para utilizar libremente mi imaginación. La imaginación es más importante que el conocimiento. El conocimiento es limitado. La imaginación abarca todo el mundo" (citado en David Garfinkle y Richard Garfinkle, El universo en tres pasos, Barcelona : Crítica, 2010, p. 15).

34. Me refiero a la célebre metáfora de William Blake (luego retomada en la novela homónima de Aldous Huxley): "If the doors of perception were cleansed / everything would appear to man as it is, infinite" (The Marriage of Heaven and Hell, Boston : John W. Luce \& Co., 1906, p. 26). El poema del que proceden estos versos, The Marriage of Heaven and Hell (1790), es por cierto otro notable caso de invención iconotextual, toda vez que combina la poesía con dibujos e ilustraciones del autor de hecho cabe sugerir que el modo visionario de "ampliación de la percepción" propuesto por Blake no es ajeno a la poética intermedial que pone en juego ese texto.

35. M. Levrero, op. cit., pp. 108-109.

36. M. Levrero, Fauna / Desplazamientos, Buenos Aires : Ediciones de la Flor, 1987, p. 90.

37. Ibid, p. 90.

38. Véase L. Wittgenstein, Investigaciones filosóficas, Barcelona : Crítica, 2004, p. 447.

39. Ibid, p. 447. 
40. M. Levrero, El portero y el otro, pp. 90-91.

41. Ibid, p. 108.

42. Irrupciones I, p. 38.

43. Ibid, p. 37.

44. En conversación con Pablo Silva Olázabal afirma por ejemplo : "Probablemente [...] tenga razón Lacan, que detrás de la imagen está la palabra. (Yo agrego que la palabra está encriptada, está en un idioma del inconsciente -o quizás a un nivel tan profundo que, sin estar encriptada, no podemos captarla directamente-y sólo podemos recuperarla cuando se hace imagen; agarramos la imagen y la volvemos a traducir a palabra, en nuestro lenguaje.)". P. Silva Olazábal, Conversaciones con Mario Levrero, Montevideo : Ediciones Trilce, 2008, p. 34.

45. Véase S. Freud, La interpretación de los sueños, en particular el capítulo 7, "La elaboración onírica”, Madrid : Alianza Editorial, 1966, pp. 307-434.

46. Véase, respectivamente, R. Jakobson, "En torno a los aspectos lingüísticos de la traducción”, en Ensayos de lingüística general, Madrid: Seix Barral, 1981, pp.67-77, y H. de Campos, "Da tradução como criação e como critica", en Metalinguagem: ensaios de teoria e crítica litéraria, Rio de Janeiro:Vozes, 1967, pp. 21-38.

47. Véase J. Montoya Juárez, op. cit., pp. 76-95.

48. En el Libro de los pasajes Walter Benjamin observa: "Toda imagen verdadera produce turbulencias. Nadar a contracorriente del remolino. Como en arte lo decisivo es : cepillar el mundo a contrapelo" (Das Passagen-Werk, Frankfurt am Main, Suhrkamp, 1991, p. 1011) [mi traducción].

49. M. Levrero, op. cit., pp. 142-143.

50. A. Méndez Rubio, (FBI) Fascismo de baja intensidad, Santander : La Vorágine, 2015.

51. En cuanto a la noción de intermedialidad véanse los trabajos de Rajewski, Wagner y Jost incluidos en la bibliografía.

52. Véase V. Flusser, $O$ universo das imagens técnicas: elogio da superficialidade, São Paulo: Annablume, 2008. Como observa Montoya Juárez, la narrativa de Levrero puede pensarse como "una máquina que atraviesa los pasajes entre la vigilia y el sueño en la era de su reproductibilidad técnica", op. cit., p. 75.

53. Op. cit., p. 23.

54. F. Hernández, "El acomodador", en Obras completas II, Madrid : Siglo XXI, 1994, p. 82.

55. Ibid, pp. 23-25.

56. M. Levrero, Irrupciones II, p. 69.

57. Véase J. Lacan, El seminario. Libro 11. Los cuatro conceptos fundamentals del psicoanálisis. 1964, Buenos Aires: Paidós, 1997.

58. M. Levrero, op. cit., p. 71.

59. Una versión extrema de esa crítica es la cita de Carl Jung que propone al final de otra de sus "irrupciones" : "Se encomienda a la palabra aquello que no puede expresarse por medios honrados. (Carl Gustav Jung, "Paracélsica")” (Irrupciones I, p. 48). Otra, más matizada, la que sugiere en su novela corta Desplazamientos: "Se me ocurre que la verdad profunda de las cosas es necesariamente difusa, imprecisa, inexacta ; que el espíritu se alimenta del misterio y huye y se disuelve cuando lo que llamamos precisión o realidad intenta fijar a las cosas en una forma determinada -o en un concepto" (Fauna / Desplazamientos, Buenos Aires : Ediciones de la Flor, 1992, p. 145).

60. "Obligado o traicionado por mí mismo a decir cómo hago mis cuentos, recurriré a explicaciones exteriores a ellos. No son completamente naturales, en el sentido de no intervenir la conciencia. Eso me sería antipático. No son dominados por una teoría de la conciencia. Eso me sería extremadamente antipático. [...] Lo más seguro de todo es que yo no sé cómo hago mis cuentos, porque cada uno de ellos tiene su vida extraña y propia. Pero también sé que viven peleando con la conciencia para evitar los extranjeros que ella le recomienda" (F. Hernández, Obras completas II, Madrid : Siglo XXI, 1997, pp. 175-176). 
61. “En un momento dado pienso que en un rincón de mí nacerá una planta. La empiezo a acechar creyendo que en ese rincón se ha producido algo raro, que podría tener porvenir artístico. [...] Al mismo tiempo ella crecerá de acuerdo a un contemplador al que no hará mucho caso si él quiere sugerirle demasiadas intenciones o grandezas" (F. Hernández, op. cit., p. 175).

62. M. Levrero, op. cit., p. 70.

63. Ibid., pp. 71-72.

64. Op. cit., p. 52.

65. M. Levrero, op. cit., p. 86.

66. Para esta noción véase W. Mitchell, op. cit., pp. 39-78.

67. M. Levrero, op. cit., p. 86.

68. Para un lúcido análisis del gesto de la "escritura imposible" en el "Diario de la Beca" de La novela luminosa (2005) véase el ensayo de Graciela Montaldo incluido en la bibliografía. Sobre el gesto de escribir mal y las poéticas de lo ilegible en la literatura latinoamericana véase mi ensayo La escritura errante : ilegibilidad y políticas del estilo en Latinoamérica, Madrid/Frankfurt am Main : Iberoamericana-Vervuert, 2015.

69. M. Levrero, Irrupciones I, p. 123.

70. Ibid., p. 71.

71. La noción de "arabesco" es central en las reflexiones narratológicas del primer romanticismo, con el que cabe vincular la poética de la ficción levreriana, como ya lo viera José Pedro Díaz en un temprano ensayo ("Del inextinguible romanticismo: la imaginación de Mario Levrero", en La máquina de pensar en Mario, op.cit., pp.21-26). Friedrich Schlegel observa en uno de sus fragmentos poetológicos: "Lo esencial en la novela es la forma caótica -arabesco, cuento de hadas" (Literarische Notizen, 1797-1801, Berlín: Ullstein, 1980, p. 180) [mi traducción]. En la reflexión de Schlegel, la fantasía y el arabesco están estrechamente ligadas a la noción de Witzes decir, al ejercicio libérrimo del humor y el ingenio en cuanto quiebre de la linealidad y la lógica inherentes al discurso racional. Véase Kritische Friedrich Schlegel Ausgabe, vol. XVI, Munich : Ferdinand Schöningh, 1956, p. 117.

\section{RESÚMENES}

Este ensayo explora la relación entre lo visible y lo legible en la obra de Mario Levrero. Partiendo de la noción de Wittgenstein de "vivencia visual" y de desarrollos recientes en las teorías de la imagen y en los estudios de cultura visual, mi lectura se enfoca en las bizarras combinaciones que genera la relación imagen/palabra en los textos de Levrero, en particular en las escenas de "visión de la escritura", que suelen conllevar varias formas de extrañamiento (inter)semiótico.

Cet article explore la relation entre le visible et le lisible dans l'oeuvre de Mario Levrero. À partir de la réflexion de Wittgenstein sur le "voir" et des récents développements dans les théories de l'image et dans les études de la culture visuelle, ma lecture se concentre sur les combinaisons bizarres générées par la relation image/mot dans les textes de Levrero, et en particulier sur les scènes de "vision de l'écriture", qui comportent diverses formes d'étrangeté (inter)sémiotique.

This essay explores the relation between the visible and the readable in the work of Mario Levrero. Starting with Wittgenstein's reflection on "seeing" as well as recent developments in image theory and visual culture studies, my reading focuses on the bizarre combinations 
generated by the relation image/word in Levrero's texts and particularly on the various forms of (inter)semiotic estrangement produced by its "scenes of writing".

\section{ÍNDICE}

Mots-clés: Levrero, théorie des images, scènes d'écriture, intermedialité

Palabras claves: Levrero, teoría de la imagen, escenas de escritura, intermedialidad

Keywords: Levrero, image theory, scenes of writing, intermediality

\section{AUTOR}

JULIO PRIETO

Universität Potsdam 